\title{
Children's Sleep Habits Questionnaire in Two Subpopulations from Cape Verde and Mozambique: Exploratory and Regression Analysis
}

\author{
Children's Sleep Habits Questionnaire em Duas \\ Sub-populações de Cabo Verde e Moçambique: \\ Análise Exploratória e de Regressão
}

\author{
Inês Marques CARNEIRO ${ }^{1}$, Pedro FONSECA 2 , Rosário FERREIRA ${ }^{1,3}$ \\ Acta Med Port 2019 Oct;32(10):628-634 - https://doi.org/10.20344/amp.11841
}

\section{ABSTRACT}

Introduction: Children's sleep habits are profoundly affected by socio-economic, cultural, and environmental factors. We aim to describe the sleep habits of pediatric sub-populations from Cape Verde and Mozambique using the Children's Sleep Habits Questionnaire, and to ascertain the determinants of the questionnaire's score.

Material and Methods: We conducted cross-sectional surveys in surveillance appointments in Cape Verde and in a school in Maputo (Mozambique). The Cape Verde sample included 206 children (mean age: 6.5) and the Mozambique sample 454 children (mean age: 8). The Portuguese version of the Children's Sleep Habits Questionnaire was used to evaluate the children's sleep habits. The distributions of the questionnaire's scores across different levels of the demographic variables were compared using the Mann-Whitney and the Kruskal-Wallis tests. We used regression models to quantify the relationship between the demographic variables and the questionnaire's scores.

Results: Cape Verde sample: Questionnaire median score: 50 (range $36-81$ ). Prevalence of sleep problems: 29.9\% (cut-off $=56$ ). Prevalence of parent-reported sleep problems: $22.8 \%$. Co-sleeping: 63\%. Bedtime television: 30\%. Daytime nap: 63\%. Questionnaire scores are associated with the mother's educational level, the children's age group, and with the frequency of daytime napping. Mozambique Sample: Median Questionnaire score: 48 (range 35 - 77). Prevalence of sleep problems: 28.4\% (cut-off: 52). Percentage of parent-reported sleep problems: 6.9\%. Co-sleeping: 29\%. Bedtime television: 33\%. Daytime nap: 23\%. Questionnaire scores are associated with the mother's nationality, the father educational level, and with the frequency of bedtime television.

Discussion: Parents tend to overestimate the quality of their children's sleep. The prevalence of sleep disturbances and the cut-off values are higher than observed in previous studies, which may be due to the existence of different standards and cultural expectations across populations. Bedtime television, typically associated with more disturbed sleep, is frequent in both samples. Co-sleeping and daytime napping are frequent in the Cape Verde sample; wetting the bed is common and more prevalent than in previous studies. Bed-sharing increases the parents' awareness of their children's sleep quality, contributing to the high prevalence of parent-reported sleep problems.

Conclusion: Parent-reported sleep problems underestimate the Children's Sleep Habits Questionnaire results. This is not necessarily indicative of more disturbed sleep and might reflect differences in sleep behavior, childcare practice, and cognitions and attitudes towards the concept of 'normal' sleep.

Keywords: Cabo Verde; Child; Culture; Habits; Mozambique; Sleep; Sleep Hygiene; Sleep Wake Disorders; Surveys and Questionnaires

\section{RESUMO}

Introdução: Os hábitos de sono são influenciados por diversos factores. Pretendemos descrever os hábitos de sono de duas populações de países africanos aplicando o Children's Sleep Habits Questionnaire e determinar quais são as variáveis que mais influenciam o score do questionário.

Material e Métodos: Realizámos dois estudos transversais em consultas de saúde infantil em Cabo Verde e numa escola em Maputo, Moçambique. A amostra de Cabo Verde incluiu 206 crianças (idade média: 6,5 anos) e a amostra de Moçambique 445 crianças (idade média: 8 anos). Aplicámos a versão portuguesa do Children's Sleep Habits Questionnaire. As distribuições dos scores do questionário para diferentes níveis das variáveis demográficas foram avaliadas com os testes de Mann-Whitney e de Kruskal-Wallis. Utilizámos regressões lineares para quantificar a relação entre variáveis demográficas e o score do questionário.

Resultados: Cabo Verde: Mediana do score: 50 (36 - 81). Problemas de sono identificados pelo questionário: 29,9\% (cut-off: 56). Problemas de sono reportados pelos pais: $22,8 \%$. Partilha de cama: 63\%. Televisão antes de adormecer: $30 \%$. Sesta: $63 \%$. Moçambique: Mediana do score: 48 (35 - 77). Problemas de sono identificados pelo questionário: 28,4\% (cut-off: 52 ). Problemas de sono reportados pelos pais: $6,9 \%$. Partilha de cama: $29 \%$. Televisão antes de adormecer: $33 \%$. Sesta: $23 \%$. Variáveis que influenciam o score: educação da mãe, faixa etária da criança e sestas (Cabo Verde); nacionalidade da mãe, educação do pai, e televisão para adormecer (Moçambique).

Discussão: Os pais tendem a sobrestimar a qualidade do sono dos seus filhos. Encontrámos prevalências de problemas do sono e valores de corte mais elevados do que os obtidos em estudos anteriores, o que também se pode dever à existência de diferentes padrões e expectativas em populações com diferentes culturas. Ver televisão para adormecer é um hábito tipicamente associado a maiores perturbações no sono e é frequente em ambas as amostras. Partilha de cama e sestas são frequentes na amostra de Cabo

1. Department of Pediatrics. Hospital Santa Maria. Lisbon Academic Medical Centre. Lisbon. Portugal.

2. Center for Applied Mathematics and Economics (CEMAPRE). Lisbon School of Economics and Management (ISEG). University of Lisbon. Lisbon. Portugal.

3. Respiratory Unit. Lung Function, Sleep and Ventilation Centre. Department of Pediatrics. Hospital de Santa Maria. Lisbon Academic Medical Centre. Lisbon. Portugal.

$\triangle$ Autor correspondente: Inês Marques Carneiro. inesmcarneiro@gmail.com

Recebido: 20 de janeiro de 2019 - Aceite: 28 de maio de 2019 | Copyright @ Ordem dos Médicos 2019 
Verde; enurese noturna também é comum e mais prevalente do que em estudos anteriores. A partilha de cama aumenta a perceção que os pais têm da qualidade do sono dos seus filhos, podendo contribuir para a elevada percentagem de problemas de sono reportada pelos pais.

Conclusão: Os problemas de sono reportados pelos pais subestimam os resultados do Children's Sleep Habits Questionnaire, o que pode traduzir diferentes expectativas e atitudes face ao sono, e não necessariamente sono patológico. Estudos futuros devem estabelecer valores de corte do Children's Sleep Habits Questionnaire adaptados a cada cultura.

Palavras-chave: Cabo Verde; Criança; Cultura; Hábitos; Higiene do Sono; Inquéritos e Questionários; Moçambique; Sono; Transtornos do Sono-Vigília

\section{INTRODUCTION}

Sleep habits are known to be profoundly affected by population-specific cultural aspects, with great variation across different populations.$^{1-7}$ Cultural values and social demands influence people's sleep habits through several different channels including cultural norms, climatic factors, family size, and space availability. ${ }^{5}$ Chinese children, for example, typically sleep less than children from other countries because they systematically fall asleep later and wake up earlier due to an increased cultural pressure for academic success. ${ }^{2}$ Italian pre-school-aged children have been found to sleep less than children from the USA because they often participate in evening social activities with their parents. ${ }^{8}$ Daytime napping is another example of the impact that cultural and environmental aspects have on sleep habits, as this biphasic sleep pattern continues to be a predominant sleep practice in countries from South America, Africa and Asia. $5,7,9$ Co-sleeping is still the norm across different cultures, and bed-sharing is frequent in almost every culture in the world with the exceptions of Europe and North America. This is not necessarily due to overcrowding. Instead, it is motivated by principles like autonomy and individualism which are advocated instead of interdependence and solidarity. ${ }^{47,8}$ The media are also known to have a considerable influence on sleep habits, which is a growing problem and has been associated to a variety of sleep disturbances across different ages, including insomnia and bedtime refusal. ${ }^{3,9}$ The Children's Sleep Habits Questionnaire (CSHQ) is a 33 items questionnaire which was designed to assess children's sleep habits according to their parents perception, and has been used in several studies to examine the sleep behavior of young children. 2,3,11 The CSHQ has been adapted and validated for the Portuguese language. ${ }^{12,13}$ As far as we know, no previously collected datasets regarding the sleep habits of pediatric populations from African countries were available prior to this study. Cape Verde and Mozambique are Portuguese-speaking African countries which are historically related to Portugal. Since Portuguese is the official language in both these countries, we used the Portuguese version of CSHQ to collect data regarding the sleep patterns and sleep disturbances of African children living in the aforementioned African countries.

\section{MATERIAL AND METHODS \\ Data collection}

Cape Verde (CV) Sample - Data collection took place in the São Vicente Island between September and November of 2016, in surveillance appointments in the public health system. The included children were between 2 and 15 years old at the time of the inquiry and were waiting for a medical appointment. Only healthy children with acute illness were considered, and children with chronic diseases were excluded. The Portuguese version of the $\mathrm{CSHQ}^{13}$ was verbally answered by the children's caregivers, with reference to the week before the children getting sick. All the caregivers were native Portuguese speakers. This study was authorized by the Delegacia de Saúde of Mindelo and by the Pediatric Department of the Baptista de Sousa Hospital. Individual consent of the respondents was obtained prior to the interviews.

Mozambique (MZ) Sample - Data collection took place in November of 2017 in a Portuguese private school in Maputo, the capital city of Mozambique. The Portuguese version of $\mathrm{CSHQ}^{13}$ was delivered to the parents of 600 children with ages ranging from 4 to 13 years old. Again, all the respondents were native Portuguese speakers. The study was authorized by the School's board and individual consent of the respondents was obtained prior to the interviews.

\section{Measure}

We used the Portuguese version of CSHQ. ${ }^{13}$ Respondents were asked to recall their children's sleep behavior with reference to the week before the survey or, in case that week was in any way atypical, any other recent 'typical' week. Each CSHQ item refers to a sleep habit and is rated according to a 3-point scale: "usually" for 5 to 7 times/week (3 points), "sometimes" for 2 to 4 times/week (2 points) and "rarely" for 0 to 1 time/week (1 point). CSHQ items are conceptually grouped into eight subscales representing the following sleep domains: 1) Bedtime resistance, 2) Sleep onset delay, 3) Sleep duration, 4) Sleep anxiety, 5) Sleepwalking, 6) Parasomnia, 7) Sleep disordered breathing and 8) Daytime sleepiness. We computed the CSHQ total scores and the CSHQ subscale scores for every child, with the full-scale score including every item from the eight subscales, although consisting of only 33 items because there are two items (4 and 6) that belong to two subscales. In order to consistently have higher scores associated with more disturbed sleep, the scores respecting to items 1, 2, 3, 10, 11, and 26 were reversed. In addition to the CSHQ standard questions we have also collected information regarding demographical characteristics of the children, including the nationality of the family, parents' age and educational level, number of cohabitants and children cohabitants, and possession of own beds and bedrooms. The CSHQ also collects information regarding additional items which are not supposed to be accounted for in the CSHQ score but will be used in exploratory and regression 
analysis, including the frequency of daytime napping and the frequency of bedtime television.

\section{Study design and statistical analysis}

We computed the median and the range of the CSHQ total score, as well as the median and the range of every CSHQ subscale score and item score. We decided to use median and range instead of mean and standard deviation due to the asymmetry in the distribution of CSHQ scores (skewness coefficients: 0.76 for the $\mathrm{CV}$ sample and 0.72 for the MZ sample). Using Mann-Whitney's U-test, we assessed the existence of differences in item scores, subscale scores, and total scores across subgroups of children differing by gender and by prevalence of parent-reported sleep problems. Kruskal-Wallis' Rank sum test was used to assess the existence of differences in CSHQ scores amongst subgroups of children differing by age group, father's and mother's years of education, number of cohabitants and children cohabitants, and mother's nationality. We used Cronbach's alpha (MZ $\alpha=0.78 ; \mathrm{CV} \alpha=0.77)$ and standardized Cronbach's alpha $\left(\mathrm{MZa}_{\mathrm{s}}=0.81 ; \mathrm{CVa}_{\mathrm{s}}=0.78\right)$ to assess the internal consistency of the questionnaires. Both the aforementioned measures of internal consistency are above the recommended threshold of 0.70 , which supports the adequacy of the questionnaires. Internal consistency within CSHQ subscales ranged from $\alpha=0.41$ to $\alpha=0.75$ and from $\alpha_{\mathrm{s}}=0.48$ to $\alpha_{\mathrm{s}}=0.73$ in the MZ sample and from $\alpha=0.37$ to $\alpha=0.80$ (and $\alpha_{s}=0.35$ to $\alpha_{s}=0.82$ ) in the $\mathrm{CV}$ sample. Reliability analysis shows that there is no item that, if dropped, would result in an increase of either $\alpha$ or $\alpha_{s}$. There is a positive and statistically significant correlation between each of the CSHQ subscale scores and the CSHQ total score (every correlation that we present is a Spearman correlation). The correlation between each item's score and the CSHQ total score is also positive. Sensitivity and specificity were examined with a receiver operation characteristic (ROC) curve using the children with parent-reported sleep problems as clinical sample. We sought the cut-off values that maximized the squared sum of sensitivity and specificity, hence weighing both measures of performance equally. This resulted in an optimal cut-off value of 52 for $M Z$ sample and 56 for $\mathrm{CV}$ sample, which gives a sensitivity of 0.89 and a specificity of 0.71 for the $M Z$ sample and a sensitivity of 0.62 and a specificity of 0.76 for the CV sample. Heterogeneity between the two samples with respect to the demographic variables was assessed through chi-squared tests of homogeneity (Table 1) which lead us to conclude that the two populations are not homogeneous. Two independent analyses will therefore be conducted.

To quantify the impact that the demographic variables, as well as bedtime TV and daytime napping, have on the CSHQ scores we used log-linear regression models with the CSHQ scores as dependent variable. The regression that was fitted to the CV sample (Table 2) resulted in a $R$-squared of 0.15 , which is evidence of a reasonably good fit. The Breusch-Pagan test finds no evidence of heteroscedasticity ( $p$-value $=0.693)$ but the Durbin Watson test signals possible residual correlation ( $p$-value $=0.004)$, and hence the standard errors of the regression that we used to calculate $p$-values were obtained with Newey-West's robust covariance matrix. In this model, the mother's nationality was not included as a regressor because all mothers

Table 1 - Sample demographics and chi-squared homogeneity test comparing the distributions of gender, age category, father and mother education, number of cohabitants and children cohabitants, and mother nationality across samples

\begin{tabular}{|c|c|c|c|}
\hline & Cape Verde $n=206$ & Mozambique $n=445$ & $p$-value \\
\hline Sex, n (\%) & $n=206$ & $n=438$ & \\
\hline $\begin{array}{r}\text { Female } \\
\text { Male }\end{array}$ & $\begin{array}{l}111(53) \\
95(46)\end{array}$ & $\begin{array}{l}225(51) \\
213(49)\end{array}$ & 0.609 \\
\hline Age group (Years), n (\%) & $n=206$ & $\mathrm{n}=441$ & \\
\hline $\begin{array}{r}2-7 \\
8-10 \\
11-15\end{array}$ & $\begin{array}{l}125(61) \\
50(24) \\
31(15)\end{array}$ & $\begin{array}{l}208(47) \\
179(40) \\
57(13)\end{array}$ & $<0.001$ \\
\hline Father education, $\mathrm{n}(\%)$ & $n=136$ & $\mathrm{n}=407$ & \\
\hline $\begin{array}{l}<10 \text { years } \\
\geq 10 \text { years }\end{array}$ & $\begin{array}{l}93(68) \\
43(32)\end{array}$ & $\begin{array}{c}33(8) \\
374(92)\end{array}$ & $<0.001$ \\
\hline Mother education, $\mathrm{n}(\%)$ & $n=165$ & $n=413$ & \\
\hline $\begin{array}{l}<10 \text { years } \\
\geq 10 \text { years }\end{array}$ & $\begin{array}{c}122(74) \\
43(26)\end{array}$ & $\begin{array}{c}23(6) \\
390(94)\end{array}$ & $<0.001$ \\
\hline No. of cohabitants, $n(\%)$ & $n=167$ & $n=433$ & \\
\hline $\begin{array}{l}<5 \\
\geq 5\end{array}$ & $\begin{array}{c}62(37) \\
105(63)\end{array}$ & $\begin{array}{l}305(70) \\
128(30)\end{array}$ & $<0.001$ \\
\hline No. of cohabitant children, $\mathrm{n}(\%)$ & $n=167$ & $n=439$ & \\
\hline $\begin{array}{l}<3 \\
\geq 3\end{array}$ & $\begin{array}{l}97(58) \\
70(42)\end{array}$ & $\begin{array}{c}344(80) \\
88(20)\end{array}$ & $<0.001$ \\
\hline Mother nationality, n (\%) & Cape Verdean 206 (100) & $\begin{array}{c}\text { Mozambican } 275(64) \\
\text { Portuguese } 129(30) \\
\text { Other } 35(6)\end{array}$ & \\
\hline
\end{tabular}


Table 2 - Log-linear regression model- CV sample

\begin{tabular}{|c|c|c|c|}
\hline & & $\begin{array}{c}\text { Coefficient } \\
\text { Estimate }\end{array}$ & $p$-value \\
\hline Intercept & & 4.019 & $<0.001$ \\
\hline Age (years) & $\begin{array}{c}8-10 \\
11-15\end{array}$ & $\begin{array}{l}-0.090 \\
-0.095\end{array}$ & $\begin{array}{l}0.010 \\
0.043\end{array}$ \\
\hline Sex & Male & 0.015 & 0.559 \\
\hline No. of cohabitants & $\geq 5$ & 0.057 & 0.196 \\
\hline $\begin{array}{l}\text { No. of cohabitant } \\
\text { children }\end{array}$ & $\geq 3$ & -0.057 & 0.192 \\
\hline $\begin{array}{l}\text { Father education } \\
\text { (years) }\end{array}$ & $\geq 10$ & -0.035 & 0.315 \\
\hline $\begin{array}{l}\text { Mother education } \\
\text { (years) }\end{array}$ & $\geq 10$ & -0.075 & 0.016 \\
\hline $\begin{array}{l}\text { Falls asleep while } \\
\text { watching TV }\end{array}$ & $\begin{array}{l}\text { Sometimes } \\
\text { Usually }\end{array}$ & $\begin{array}{l}0.007 \\
0.021\end{array}$ & $\begin{array}{l}0.798 \\
0.514\end{array}$ \\
\hline Takes a Nap & $\begin{array}{l}\text { Sometimes } \\
\text { Usually }\end{array}$ & $\begin{array}{l}-0.056 \\
-0.068\end{array}$ & $\begin{array}{l}0.131 \\
0.094\end{array}$ \\
\hline Multiple R-squared & & 0.146 & - \\
\hline Residual standard error & & 0.152 & - \\
\hline F-statistic & & 1.831 & 0.056 \\
\hline Breusch-Pagan statistic & & 8.228 & 0.693 \\
\hline Durbin-Watson statistic & & 1.571 & 0.004 \\
\hline
\end{tabular}

in the CV sample are Cape Verdean. With the regression that was fitted to the MZ sample (Table 3), we obtained an $\mathrm{R}$-squared of 0.15 , which again signals a reasonably good fit. The Breusch-Pagan test and the Durbin-Watson test found no evidence of heteroscedasticity or residual correlation, respectively. Note that in the $M Z$ sample we did not include daytime napping as a regressor since the subgroup of children who "usually" took a daytime nap consisted of 25 children only.

\section{RESULTS}

\section{Sample}

CV sample - We gathered information from a total of 206 questionnaires. Approximately $90.3 \%$ of the questionnaires were answered by the children's mothers, $1.9 \%$ by fathers, $6.3 \%$ by grandmothers, and $1.5 \%$ by other relatives. Children's ages ranged from 2 to 15 years old, with a median age of 6 , and most children came from families with low educational levels (Table 1). Using the CSHQ scores, together with the optimal cut-off value of 56 , we estimated a $29.9 \%$ prevalence of sleep disorders in this sample, which is above the prevalence of parent-reported sleep problems $(22.8 \%)$.

MZ sample - We gathered information from a total of 445 questionnaires (74\% of the delivered questionnaires). There were 105 missing values, and only complete cases with respect to the variables of interest were considered. Children's ages ranged from 3 to 13 years, with a median age of 8 . Using the CSHQ scores, together with the optimal cut-off value of 52 , we estimated a $28.4 \%$ prevalence of sleep disorders in this sample, which is above the prevalence of
Table 3 - Log-linear regression model - MZ sample

\begin{tabular}{|c|c|c|c|}
\hline & & $\begin{array}{l}\text { Coefficient } \\
\text { Estimate }\end{array}$ & $p$-value \\
\hline Intercept & & 3.895 & $<0.001$ \\
\hline Age (years) & $\begin{array}{c}8-10 \\
11-15\end{array}$ & $\begin{array}{l}-0.009 \\
-0.036\end{array}$ & $\begin{array}{l}0.596 \\
0.158\end{array}$ \\
\hline Sex & Male & -0.011 & 0.478 \\
\hline No. of cohabitants & $\geq 5$ & -0.020 & 0.482 \\
\hline $\begin{array}{l}\text { No. of cohabitant } \\
\text { children }\end{array}$ & $\geq 3$ & 0.018 & 0.572 \\
\hline $\begin{array}{l}\text { Father education } \\
\text { (years) }\end{array}$ & $\geq 12$ & -0.040 & 0.044 \\
\hline $\begin{array}{l}\text { Mother education } \\
\text { (years) }\end{array}$ & $\geq 12$ & 0.018 & 0.410 \\
\hline Mother nationality & $\begin{array}{l}\text { Portuguese } \\
\text { Other }\end{array}$ & $\begin{array}{l}-0.039 \\
0.055\end{array}$ & $\begin{array}{l}\mathbf{0 . 0 2 2} \\
0.066\end{array}$ \\
\hline $\begin{array}{l}\text { Falls asleep while } \\
\text { watching TV }\end{array}$ & $\begin{array}{c}\text { Sometimes } \\
\text { Usually }\end{array}$ & $\begin{array}{l}0.111 \\
0.077\end{array}$ & $\begin{array}{l}<0.001 \\
<0.001\end{array}$ \\
\hline Multiple R-squared & & 0.149 & - \\
\hline Residual standard error & & 0.133 & - \\
\hline F-statistic & & 4.531 & $<0.001$ \\
\hline Breusch-Pagan statistic & & 14.379 & 0.213 \\
\hline Durbin-Watson statistic & & 2.040 & 0.610 \\
\hline
\end{tabular}

parent-reported sleep problems (6.9\%). Children in this sample originated mostly from families with high levels of education (Table 1). Note that $93 \%$ of the children in this sample had their own beds, and $53 \%$ had their own bedrooms.

\section{CSHQ scores}

Table 4 summarizes the distribution of CSHQ scores in both samples by subgroups of sex, age, parents' educational level, mother's nationality, number of cohabitants and number of children cohabitants. CSHQ scores ranged from 36 to 81 in the CV sample, with a median score of 50 , and ranged from 35 to 77 in the $\mathrm{MZ}$ sample, with a median of 48. For each sample, either the Mann-Whitney test or the Kruskal-Wallis test was used to assess the existence of differences in CSHQ scores within different levels of each demographic variable. CSHQ scores only seem to differ within different levels of mother's educational level (in the CV sample) and mother's nationality (MZ sample).

\section{Item analysis: Individual sleep problems and other sleep habits}

CV Sample - Using the items nomenclature, the most prevalent individual sleep problems in the CV sample are: "restless sleep" (67\%), "falling asleep in another's bed" (63\%), "awakening one time during night" (63\%), "awakened by others in the morning" (46\%), "talking during sleep" $(45 \%)$, and "being afraid of sleeping in the dark" (43\%). The less prevalent individual sleep problems are: "awaken screaming, sweating" (6\%), "alarmed by scary dream" $(10 \%)$, "holding breath or stop breathing" (13\%), "sleepwalking" (14\%), "snorting and gasping" (16\%), "struggling 
Table 4 - CSHQ scores by sex, age, parent education, number of cohabitants and mother's nationality

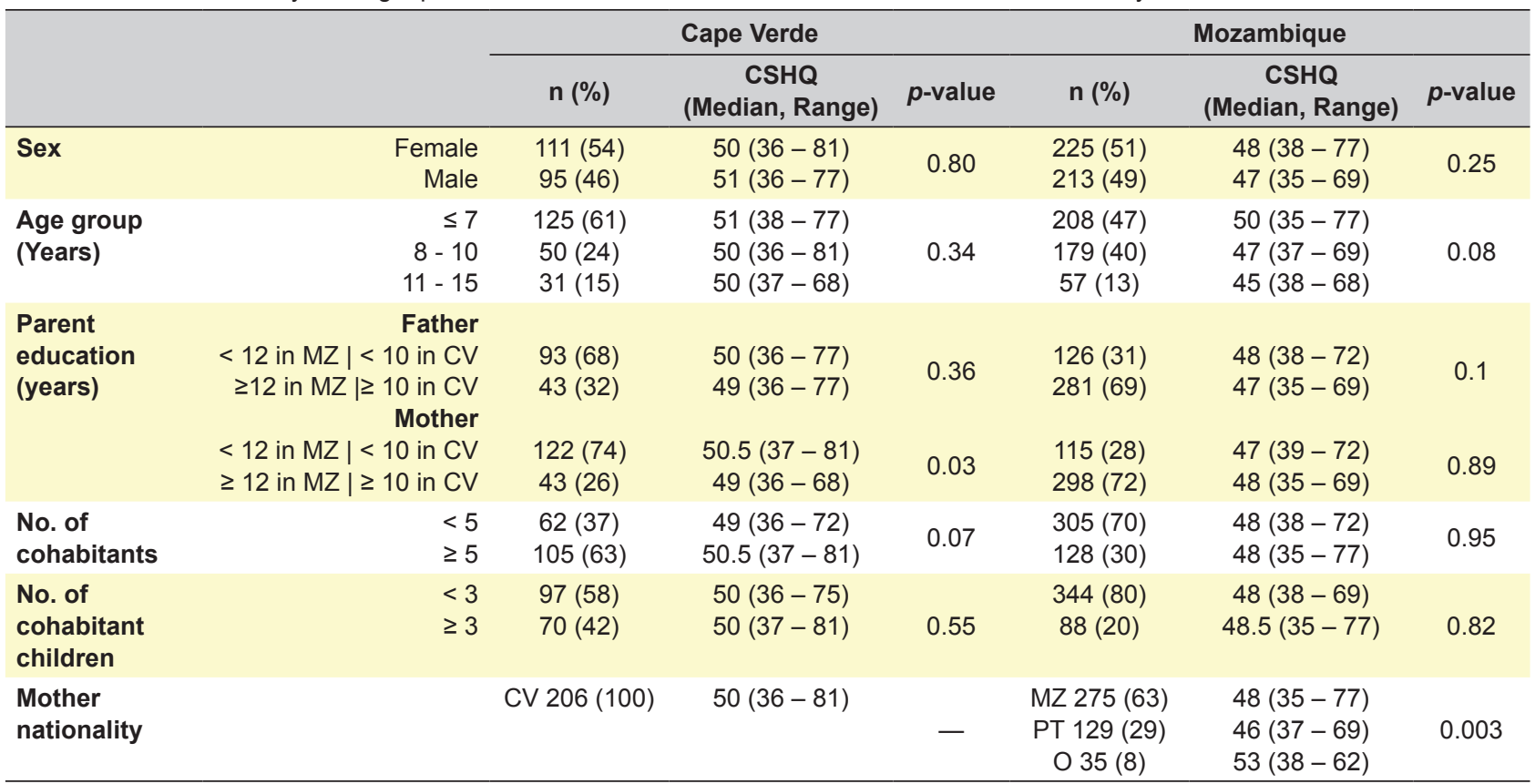

MZ: Mozambique; PT: Portugal; O: other; CV: Cape Verde

at bedtime" (17\%), and "moving to other's bed at night" $(19 \%)$. It was found that about $30 \%$ of all children in this sample "usually" or "sometimes" watch television in order to fall asleep. We found a positive sample correlation between the CSHQ total score and the score of the item "watching television to fall asleep" (correlation $=0.18, p=0.01$ ). In what concerns other sleep habits, about $12 \%$ of the children in this sample "usually" or "sometimes" need a special object to fall asleep, and about 6\% "usually" or "sometimes" need to be cradled in order to fall asleep.

MZ Sample - The most prevalent individual sleep problems in the $\mathrm{MZ}$ sample are: "awakened by others in the morning" (85\%), "does not wake by himself" $(75 \%)$, "does not fall asleep in 20 min" (60\%), "hard time getting out of bed" (49\%), "restless sleep" (41\%), and "being afraid of sleeping in the dark" (41\%). The less prevalent individual sleep problems are: "wets the bed at night" $(7 \%$, only for children $\geq 4$ years old), "stops breathing" (5\%), "awakens screaming, sweating" (4\%), "sleepwalks" (4\%), and "awakes more than once" $(5 \%)$. About $33 \%$ of the children in this sample "usually" or "sometimes" watch television in order to fall asleep. We found a positive sample correlation between the CSHQ total score and the score of the item "watch television to fall asleep" (correlation $=0.36$, $p<0.001)$. In what concerns other sleep habits, about $16 \%$ of the children in the MZ sample "usually" or "sometimes" need a special object to fall asleep, about $5 \%$ "usually" or "sometimes" need to be cradled in order to fall asleep, and 29\% "usually" or "sometimes" fall asleep in another's bed.

\section{Regression analysis}

CV Sample - The output of the log-linear model that was fitted to the CV sample can be found in Table 2. In this sample, three variables have a statistically significant effect on the CSHQ score: age, mother's educational level, and daytime napping. Cape Verdean children older than 8 years old are estimated to have CSHQ scores approximately $9 \%$ lower, on average, than Cape Verdean children younger than 8 years old. The CSHQ score is also estimated to be approximately $7 \%$ lower, on average, in children whose mothers have more than 9 years of education. Another interesting finding is that children who "usually" take a daytime nap are estimated to have CSHQ scores approximately $7 \%$ lower, on average, when compared to children who "rarely" take a daytime nap. There is no evidence of changes in the CSHQ score for children who "sometimes" take a daytime nap.

MZ Sample - The output of the log-linear model that was fitted to the $M Z$ sample can be found in Table 3. In this model, the demographic variables with a statistically significant impact on the CSHQ scores are the father's educational level and the mother's nationality. According to this model, children whose fathers have more than 11 years of education are estimated to have CSHQ scores approximately $4 \%$ lower, on average, than children whose fathers have 11 or less years of education. Furthermore, the CSHQ scores of the children of Portuguese mothers are estimated to be approximately $3 \%$ lower, on average, than the scores of the children of Mozambican mothers. Regarding bedtime television, this model finds evidence that children who "sometimes" fall asleep while watching TV have CSHQ scores approximately $12 \%$ higher, on average than children who "rarely" fall asleep while watching TV. On the other hand, children who "usually" fall asleep while watching TV are estimated to have CSHQ scores approximately $7 \%$ higher, on average, than children who "rarely" fall asleep while watching TV. 
Table 5 - Sleep patterns by age

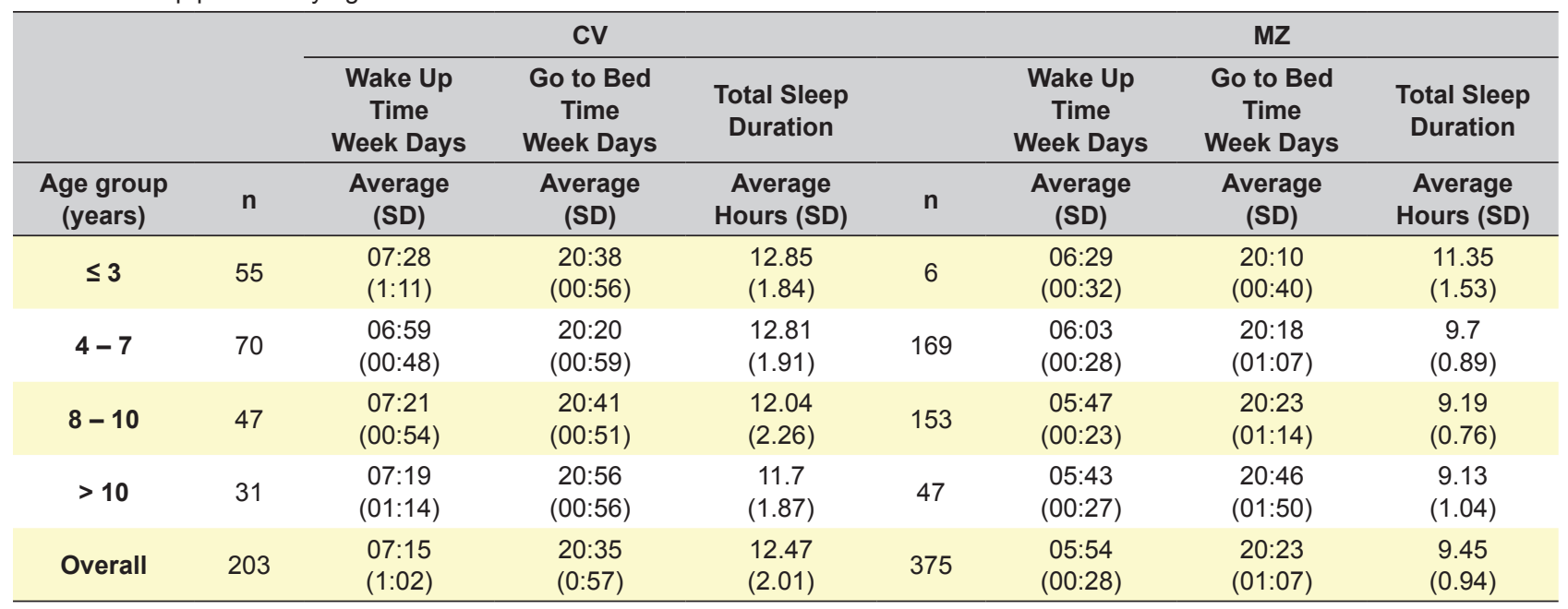

\section{Sleep/Wake patterns}

Some descriptive statistics respecting to wake up time, bedtime, and average sleep duration (including naptime, weekdays and weekends) are presented in Table 5.

CV Sample - The average sleep duration in the CV sample is 12.5 hours (including naps, weekdays and weekends), with a standard deviation of 2.01. In this sample about $64 \%$ of children take a nap ("usually" or "sometimes"), corresponding to $78 \%$ of the children under 4 years old, $80 \%$ between 4 and 7 years old, $46 \%$ between 7 and 10 years old, and $29 \%$ of the children older than 10 years old.

MZ Sample - The average sleep duration in the MZ sample is 9.45 hours (including nap, weekdays and weekends), with a standard deviation of 0.94 . In the $\mathrm{MZ}$ sample only about $23 \%$ of the children take a nap ("usually" or "sometimes"), corresponding to $62 \%$ of the children under 4 years old, $22 \%$ between 4 and 7 years old, $16 \%$ between 7 and 10 years old, and $27 \%$ of the children older than 10 years old.

\section{DISCUSSION}

The two sub-populations that have been analyzed in this study exhibited a high prevalence of sleep disturbances. We have obtained cut-off values that are higher than the ones that could previously be found in the relevant CSHQ-related literature, which suggests that individual sleep problems are more prevalent in the sub-populations that we have analyzed than in the sub-populations that were used in previous studies. The cut-off values used by Owens, ${ }^{11}$ Arriaga, ${ }^{14}$ and Silva ${ }^{12}$ would not be appropriate for our samples as they would result in $95 \%, 87 \%$, and $62 \%$ of the children testing positive for sleep disturbances in the CV sample, respectively, and in $96 \%, 88 \%$, and $63 \%$ of the children testing positive for sleep disturbances in the $\mathrm{MZ}$ sample, respectively. Parent's perception of disturbed sleep has been found to be lower than the percentage of sleep disturbances identified by the CSHQ. This, together with the high cut-off values that we have obtained, is not necessarily indicative of more disturbed sleep but instead can reflect the existence of different cultural expectations that result in different perceptions of whether or not certain sleep practices are considered to be normal. ${ }^{5,6}$ Since sleep deprivation is deleterious to cognition and to emotional and social behavior, also having negative metabolic effects, it is important to stipulate what practices are deemed as good sleep practices in each population..$^{1,15}$

In the CV sample, the average CSHQ score is estimated to be lower for children whose mothers have more than 9 years of education, children older than 8 years old, and children who "usually" take a daytime nap. In the MZ sample, the average CSHQ score is estimated to be lower for children whose fathers have more than 11 years of education, children with Portuguese mothers, and children who "rarely" watch television to fall asleep.

In what concerns sleeping routines, neither the utilization of "transitional objects" (with the exception of pacifiers) nor the habit of "cradling to fall asleep" have been found to be common practices in any of sub-populations that we have analyzed. Bed time rituals are known to be more prevalent in western countries than in more traditional cultures. ${ }^{4-6}$ As the children's age increases, bedtime has been found to be increasingly delayed and sleep duration has been found to decrease in both sub-populations. Watching television is a frequent behavior in both samples. This habit is associated with more disturbed sleep across subgroups of children of different nationalities, which is why international recommendations advise against the practice of watching television before going to sleep. ${ }^{16}$ Taking a daytime nap has been found to be very common in the CV sample, even for older children. Daytime sleep practices vary widely across different cultures and races, with daytime napping being very popular, for example, in places with high daytime temperatures. ${ }^{4}$ Co-sleeping has been found to be frequent in the CV sample. The high prevalence of breastfeeding is one factor that can contribute to a greater proximity between the mother and the younger children, hence influencing routine sleep habits since birth. ${ }^{4,5,7}$ Bed-sharing raises the parents awareness regarding their children's sleep habits and can explain the higher prevalence of parent-reported individual sleep problems. ${ }^{17}$ The CV sample has a higher prevalence of individual problems when compared to the results 
of similar surveys conducted in the USA and China, ${ }^{2}$ with every individual sleep problem being present in more than $10 \%$ of the observations with exception of the item "awaken screaming, sweating". The MZ sample exhibited a higher prevalence of individual sleep problems when compared to the USA and China, but showed a lower prevalence when compared to $\mathrm{CV}^{2}$ Co-sleeping has been found to be associated with increased nocturnal enuresis in children aged from 9 to 12 years old. ${ }^{18}$ Nocturnal enuresis is known to be more prevalent in the black race. ${ }^{19}$ Wetting the bed has been found to be common in the CV sample, and even more prevalent when compared to other studies. ${ }^{2,14}$

The main limitation of this study is the possible presence of sampling bias, aggravated by self-selection in the $\mathrm{MZ}$ sample, which means that this study's conclusions are not necessarily generalizable to the entire population of the analyzed countries. This is, however, one of the few studies that uses the CSHQ in a low-income context and it has allowed us to evaluate children's sleep habits across subgroups with the same scholar routines and environmental and solar exposure but with different cultural backgrounds.

\section{CONCLUSION}

As far as we know, this is the first study to address the topic of sleep habits and sleep disturbances using data from subpopulations of African children living in African countries. We found higher than usual CSHQ scores, which is not necessarily indicative of more disturbed sleep but instead might reflect differences in sleep behavior, childcare practices, and different cognitions and attitudes towards normal sleep behavior. CSHQ scores have been found to be associated with the children's age, mother's educational level, and daytime napping in the CV sample and with the mother's nationality, father's educational level, and frequency of bedtime television in the MZ sample. Sleep habits like bedtime,

\section{REFERENCES}

1. Bathory E, Tomopoulos S. Sleep regulation, physiology and development, sleep duration and patterns, and sleep hygiene in infants, toddlers, and preschool-age children. Curr Probl Pediatr Adolesc Health Care. 2017; 47:29-42.

2. Liu X. Sleep patterns and sleep problems among schoolchildren in the United States and China. Pediatrics. 2005;115:241-9.

3. Van Litsenburg RR, Waumans RC, Van Den Berg G, Gemke RJ. Sleep habits and sleep disturbances in Dutch children: a population-based study. Eur J Pediatr. 2010;169:1009-15.

4. Giannotti F, Cortesi F. Family and cultural influences on sleep development. Child Adolesc Psychiatr Clin N Am. 2009;18:849-61.

5. Jenni OG. Children's sleep: an interplay between culture and biology. Pediatrics. 2005;115:204-16.

6. Mindell JA, Sadeh A, Wiegand B, How TH, Goh DY. Cross-cultural differences in infant and toddler sleep. Sleep Med. 2010;11:274-80.

7. Mileva-Seitz VR, Bakermans-Kranenburg MJ, Battaini C, Luijk MP. Parent-child bed-sharing: the good, the bad, and the burden of evidence. Sleep Med Rev. 2017;32:4-27.

8. Ottaviano S, Giannotti F, Cortesi F, Bruni O, Ottaviano C. Sleep characteristics in healthy children from birth to 6 years of age in the urban area of Rome. Sleep. 1996;19:1-3.

9. Nunn CL, Samson DR, Krystal AD. Shining evolutionary light on human sleep and sleep disorders. Evol Med Public Heal. 2016;2016:227-43.

10. Owens J, Maxim R, McGuinn M, Nobile C, Msall M, Alario A. Televisionviewing habits and sleep disturbance in school children. Pediatrics. 1999;104:e27.

11. Owens JA, Spirito AM. The children's sleep habits questionnaire bedtime rituals, co-sleeping, and daytime napping are influenced by cultural, socio-economic, and environmental factors and hence the background of the family should be taken into consideration when evaluating children's sleep habits. Future research should seek optimal CSHQ cut-off values for different cultures and assess the existence of differences in sleep habits across different populations by measuring the impact that particular sleep practices have on cognition, behavior, emotions, and metabolic factors in order to adapt sleep recommendations to individual populations.

\section{ACKNOWLEDGMENTS}

We would like to thank the Board of the private school in Maputo, the Delegacia de Saúde of Mindelo and Department of Pediatrics of Hospital Baptista de Sousa in Cape Verde, for granting us permission to conduct the questionnaire, and to the caregivers of children that agreed to participate in the study.

\section{PROTECTION OF HUMANS AND ANIMALS}

The authors declare that the procedures were followed according to the regulations established by the Clinical Research and Ethics Committee and to the Helsinki Declaration of the World Medical Association.

\section{DATA CONFIDENTIALITY}

The authors declare having followed the protocols in use at their working center regarding patients' data publication.

\section{CONFLICTS OF INTEREST}

All authors report no conflict of interest.

\section{FUNDING SOURCES}

This research received no specific grant from any funding agency in the public, commercial, or not-for-profit sectors.

(CSHQ): psychometric properties of a survey instrument for schoolaged children. Sleep. 2000;23:1043-51.

12. Silva FG, Silva CR, Braga LB, Neto AS. Portuguese Children's Sleep Habits Questionnaire - validation and cross-cultural comparison. J Pediatr. 2014;90:78-84.

13. Ferreira VR, Carvalho LB, Ruotolo F, de Morais JF, Prado LB, Prado GF. Sleep disturbance scale for children: translation, cultural adaptation, and validation. Sleep Med. 2009;10:457-63.

14. Arriaga C, Brito S, Gaspar P, Luz A. Hábitos e perturbações do sono: caracterização de uma amostra pediátrica na comunidade. Acta Pediatr Port. 2015;46:367-75.

15. Mindell JA, Owens J, Alves R, Bruni O, Goh DY, Hiscock H, et al. Give children and adolescents the gift of a good night's sleep: a call to action. Sleep Med. 2011;12:203-4.

16. Guram S, Heinz P. Media use in children: American Academy of Pediatrics recommendations 2016. Arch Dis Child - Educ Pract Ed. 2018;103:99-101.

17. Waumans RC, Terwee CB, Van den Berg G, Knol DL, Van Litsenburg RR, Gemke RJ. Sleep and sleep disturbance in children: reliability and validity of the Dutch version of the Child Sleep Habits Questionnaire. Sleep. 2010;33:841-5.

18. Ma J, Li S, Jiang F, Jin X, Shen X, Li F. Co-sleeping and childhood enuresis in China. J Dev Behav Pediatr. 2014;35:44-9.

19. Shreeram S, He JP, Kalaydjian A, Brothers S, Merikangas KR. Prevalence of enuresis and its association with attention-deficit/hyperactivity disorder among U.S. children: results from a nationally representative study. J Am Acad Child Adolesc Psychiatry. 2009;48:35-41. 